\title{
PRODUTOS APÍCOLAS E SAÚDE HUMANA: UMA REVISÃO INTEGRATIVA
}

\author{
BEE PRODUCTS AND HUMAN HEALTH: AN INTEGRATIVE REVIEW
}

\section{Ankilma do Nascimento Andrade Feitosa ${ }^{1 *}$, Maria Amanda Laurentino Freires ${ }^{2}$, Thaise de Abreu Brasileiro Sarmento ${ }^{3}$, Luciana Modesto de Brito ${ }^{4}$, Raimunda Leite de Alencar Neta $^{5}$, \& Patrício Borges Maracajá ${ }^{6}$}

\author{
12345 Faculdade Santa Maria, Cajazeiras. ${ }^{6}$ Docente da Universidade Federal de Campina Grande. \\ 1*ankilmar@hotmail.com 2 m.amandafreires@hotmail.com ${ }^{3}$ thaiseabreu@ hotmail.com \\ ${ }^{4}$ lucianamodesto@ hotmail.com ${ }^{5}$ alencarraimunda886@gmail.com ${ }^{6}$ patriciomaracaja@gmail.com
}

\section{ARTIGO INFO.}

\section{Recebido em: 03.10.2020}

Aprovado em: 23.10.2020

Disponibilizado em: 04.11.2020

\section{Palavras-chave:}

Antibacterianos; Abelhas; Mel; Fungos; Bactérias.

\section{KEYWORDS:}

Anti-bacterial agents; Bees; Honey; Fungi; Bacteria.

\section{*Autor Correspondente: Feitosa, A. do N. A.}

\section{RESUMO}

Com o crescimento dos microrganismos multirresistentes, buscar alternativas para infecções bacterianas ou fúngicas tornou-se uma meta para pesquisadores em diversos países, a fim de obter métodos eficazes e seguros. Neste cenário, incluem-se os produtos apícolas, sendo os principais a cera, o mel, a geleia real e a própolis, capazes de se tornarem grandes aliados no tratamento de microrganismos patogênicos. Visto isso, o objetivo deste trabalho foi analisar as propriedades antimicrobianas contra bactérias e fungos do mel, geleia real e da própolis. Trata-se de uma revisão integrativa da literatura, na qual foram utilizandas as bases de dados: SciELO, PubMed e LILACS para pesquisa através dos Descritores em Ciências da Saúde, incluindo artigos originais, de revisão, relatos de caso, publicados em português, inglês e/ou espanhol, disponíveis na íntegra e gratuitamente, e publicados entre 2010 e 2020. Foram incluídos oito artigos, todos recuperados da base de dados PubMed, os quais revelaram o grande potencial que o mel e a própolis possuem no combate a infecções causadas mesmo por bactérias multirresistentes, porém nenhum estudo abordou tal atividade em fungos. É sugerido que haja o desenvolvimento de novos estudos sobre o tema, principalmente no Brasil, e aplicando tais produtos em fungos e outros seres vivos de relevância clínica, com desenhos amostrais bem delineados, com o objetivo maior de auxiliar na oferta de uma assistência à saúde mais eficiente e de qualidade.

\begin{abstract}
With the growth of multi-resistant microorganisms, seeking alternatives to bacterial or fungal infections has become a goal for researchers in several countries, in order to obtain effective and safe methods. This scenario includes bee products, the main ones being wax, honey, royal jelly and propolis, capable of becoming great allies in the treatment of pathogenic microorganisms. Thus, the objective of this work is to analyze the antimicrobial properties against bacteria and fungi of honey, royal jelly and propolis. This is an integrative literature review, using the: SciELO, PubMed and LILACS databases for research through Health Sciences Descriptors, including original, review articles, case reports, published in Portuguese, English and/or Spanish, available in full and free of charge, and published in the period from 2010 to 2020. Eight articles were included, all retrieved from the PubMed database, which revealed the great potential that honey and propolis have in fighting infections caused even by multi-resistant bacteria, but no study addressed such activity on fungi. New studies should be developed on the subject, mainly in Brazil, applying such products to fungi and other living beings of clinical relevance, with well-designed samples, with the main objective of helping offer efficient and effective health care of quality.
\end{abstract}




\section{INTRODUÇÃO}

O homem, como todos os seres vivos do planeta, é totalmente dependente dos recursos naturais, sem os quais sua existência seria impossível. O meio ambiente provê alimentos, água, medicamentos - destaca-se, aqui, a penicilina, originária de um fungo -, dentre inúmeros outros insumos que garantem uma vida digna e saudável aos seus habitantes (Hofling, 2016).

Desde os primórdios da existência humana, plantas, animais e outros seres vivos vem sendo utilizados para além da alimentação, incluindo-se tratamento e cura de doenças, dores e feridas. Com o passar dos tempos, a cura pelos métodos naturais foi sendo substituída pelos medicamentos chamados alopáticos, cujo objetivo é produzir efeitos contrários aos da enfermidade que visa a combater (Neto, \& Rossi, 2018).

Atualmente, com a vida frenética dos grandes centros urbanos e almejando uma vida mais saudável, o número de pessoas que buscam as Práticas Integrativas e Complementares (PIC) vem sendo cada vez maior. Tais práticas são regulamentadas pelo Ministério da Saúde e oferecidas pelo Sistema Único de Saúde (SUS), e utilizam recursos terapêuticos baseados em conhecimentos tradicionais, cujo objetivo é prevenir enfermidades ou tratar paliativamente doenças crônicas (Brasil, 2019).

Além da busca por alternativas mais naturais, tem-se o crescimento da resistência aos antimicrobianos, que vem se tornando um sério problema de saúde pública, sendo considerada uma das maiores ameaças globais à saúde, segurança dos alimentos e desenvolvimento (Opas, 2017). Com isso, medicamentos naturais têm sido utilizados como uma forma de conter a resistência aos antimicrobianos e trazer qualidade de vida e, quando possível, cura para diversos pacientes.

Neste contexto, inserem-se as abelhas, seres vivos de extrema importância para o meio ambiente, cujos principais produtos conhecidos são o mel, a própolis, a cera, a geleia real e o pólen (Dorazio, 2017). As abelhas são pertencentes à ordem Hymenoptera e à superfamília dos Apoidea (grupo Apiformes) e dividem-se em cerca de 20 mil espécies, sendo Apis mellifera a mais conhecida (Abelha, 2017).

No Brasil, a apicultura iniciou no século XIX, mais especificamente em 1839, com a introdução da espécie Apis mellifera pelo padre Antonio Carneiro, trazida da região do Porto, em Portugal. Outras subespécies de $A$. mellifera foram introduzidas por imigrantes alemães e italianos entre os anos de 1845 e 1880, nas regiões sudeste e sul do Brasil (Abelha, 2017).

Em termos de utilidades dos produtos apícolas, neste estudo, o foco será no mel e na própolis. O mel, consumido desde a antiguidade, é ricamente energético, rico em aminoácidos e possui diversos usos para os seres humanos. Já a própolis é uma substância pegajosa, suja função é higienizar a colmeia e é utilizada na fabricação de medicamentos (Duarte, 2019).

$\mathrm{O}$ presente estudo justifica-se pelo crescente interesse em produtos naturais tanto pela população como pelos profissionais da saúde, assim como o aumento de pesquisas que visam a estudar os efeitos de tais produtos em diversas enfermidades e organismos patogênicos aos seres humanos, principalmente quando relacionados a organismos multirresistentes. Visto isso, o

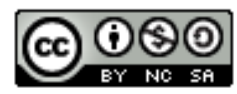


objetivo deste trabalho foi analisar as propriedades antimicrobianas contra bactérias e fungos do mel, geleia real e da própolis.

\section{Metodologia}

O estudo trata-se de uma revisão integrativa da literatura, que de acordo com Sousa \& Santos (2016), o estudo de revisão integrativa, consiste em um método que irá proporcionar uma síntese dos conhecimentos e a incorporação da aplicabilidade dos resultados de estudos significativos para a prática.

A revisão integrativa segue seis fases, a saber: o primeiro passo consiste na elaboração de uma pergunta norteadora, em seguida é realizada uma busca ou amostragem na literatura, onde posteriormente é realizada uma coleta de dados, em seguia é construída uma análise crítica dos estudos utilizados para compor a revisão, discussão dos resultados encontrados e para finalizar é realizada uma apresentação da revisão integrativa (Sousa, \& Santos, 2016).

Na primeira fase, visando a atingir os objetivos almejados pelo presente estudo, formulou-se a seguinte questão norteadora: Quais são as propriedades antimicrobianas contra fungos e bactérias do mel, da geleia real e da própolis? A partir da pergunta norteadora, buscaram-se os descritores em português indexados nos Descritores em Ciências da Saúde (DeCS) e seus correspondentes em inglês e espanhol, para pesquisa nas bases de dados, sendo eles: antibacterianos (anti-bacterial agents/antibacterianos), abelhas (bees/abejas), mel (honey/miel), fungos (fungi/hongos) e bactérias (bactéria/bacterias). Além disso, destaca-se que foram utilizados os seguintes operadores Booleanos: “AND" e "OR", para realizar o cruzamento dos descritores.

Na segunda fase, realizou-se a busca nas bases de dados selecionadas: PubMed, Literatura Latino-Americana e do Caribe em Ciências da Saúde (LILACS) e Scientific Electronic Library Online (SciELO). Utilizaram-se como critérios de inclusão para este trabalho: artigos originais, de revisão, relatos de caso, publicados em português, inglês e/ou espanhol, disponíveis na íntegra e gratuitamente, e publicados no período compreendido entre os anos de 2010 e 2020. O período definido corresponderia aos últimos 10 anos, porém, na elaboração do presente trabalho, o ano de 2020 encontra-se em seu quinto mês e, assim, a fim de completar os 10 anos, o ano de 2010 foi incluído. Foram excluídos artigos que tratavam apenas de estudos com animais e aqueles no qual abordavam outras espécies de abelhas sem propriedade antimicrobiana comprovada.

$\mathrm{Na}$ terceira fase, ocorreu a coleta de dados nas bases supracitadas, ou seja, foram extraídos os dados dos artigos selecionados na fase anterior. Para isso, foi elaborado um instrumento próprio contendo as seguintes informações dos estudos incluídos na amostra: autor(es), título, revista, ano de publicação, país de origem, objetivo(s), principais achados e nível de evidência.

$\mathrm{Na}$ quarta fase, foi realizada uma análise criteriosa em todos os estudos incluídos na revisão. Na quinta fase, os resultados obtidos foram discutidos à luz da literatura pertinente, destacando os principais achados e contribuições com foco no tema escolhido para o presente trabalho. Além disso, para facilitar a compreensão e sintetizar os dados encontrados, estes foram organizados em forma de quadros e gráficos. Na sexta e última fase, fez-se a apresentação da

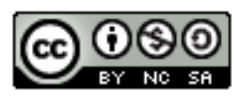


revisão integrativa de maneira clara e objetiva, a fim de propiciar ao leitor a plena compreensão e análise crítica (Sousa \& Santos, 2016).

\section{Resultados E DiscuSSÃo}

Foram pesquisados trabalhos nas bases de dados SciELO, PubMed e LILACS. Na SciELO, empregando-se as combinações antibacterianos AND abelhas AND mel AND fungos AND bactérias, antibacterianos AND abelhas AND mel AND fungos, antibacterianos AND abelhas AND mel AND bactérias, antibacterianos AND mel AND fungos AND bactérias, nenhum artigo foi encontrado. Combinando-se mel AND abelhas AND fungos AND bactérias, encontrou-se um estudo, não incluído na amostra por não abordar o tema de interesse. Utilizando-se a combinação antibacterianos AND mel AND bactérias, encontrou-se um artigo, não incluído na amostra final por ter sido publicado em 2008, estando fora do recorte temporal estabelecido nos critérios de inclusão.

Na PubMed, empregando-se ((((anti-bacterial agents) AND (bees)) AND (honey)) AND (fungi)) AND (bacteria), foram encontrados 72 resultados. Aplicando-se o filtro ano - 2010 a 2020, a quantidade reduziu para 54 artigos. Após realizar a leitura dos títulos e dos resumos, 46 estudos foram descartados, pois não compreenderam o objetivo do estudo, restando oito artigos para inclusão na amostra final e leitura na íntegra.

Na LILACS, como a pesquisa limita o uso de apenas três descritores, testou-se, primeiramente, a combinação antibacterianos AND mel AND fungos, resultando em dois trabalhos, não incluídos, tendo em vista que um estava repetido em outra base de dados e o outro era de 2009, estando fora do limite temporal estabelecido. Ao utilizar a combinação antibacterianos AND mel AND bactérias, foram encontrados quatro estudos, não sendo selecionado nenhum trabalho porque um encontrava-se repetido em outra base de dados e os outros três foram publicados fora do recorte temporal estabelecido.

Desta forma, foram obtidos oito artigos, todos da base de dados PubMed, para compor esta revisão integrativa, os quais foram lidos na íntegra e detalhadamente. O Quadro 1 mostra as informações referentes ao título, autor(es)/país de origem, periódico/ano de publicação, objetivo(s) e principais achados

Tabela 1. Título, autor(es)/país de origem, periódico/ano de publicação, objetivo(s) e principais achados dos artigos incluídos nesta revisão integrativa. 2020.

\begin{tabular}{|c|c|c|c|c|}
\hline Título & $\begin{array}{c}\text { Autor(es)/ } \\
\text { País de origem }\end{array}$ & $\begin{array}{l}\text { Periódico/ } \\
\text { Ano de } \\
\text { publicação }\end{array}$ & Objetivo(s) & Principais achados \\
\hline $\begin{array}{c}\text { Biological } \\
\text { applications of } \\
\text { honeys produced } \\
\text { by Apis mellifera }\end{array}$ & $\begin{array}{l}\text { Montenegro, G., \& } \\
\text { Mejías E. } \\
\text { Chile }\end{array}$ & $\begin{array}{l}\text { Biological } \\
\text { Research } \\
2013\end{array}$ & $\begin{array}{c}\text { Descrever as } \\
\text { principais } \\
\text { propriedades } \\
\text { biológicas benéficas } \\
\text { do mel chileno } \\
\text { produzido pela Apis } \\
\text { mellifera. }\end{array}$ & $\begin{array}{c}\text { Em termos de } \\
\text { propriedade antibiótica, } \\
\text { o mel de A. mellifera } \\
\text { mostrou-se eficaz } \\
\text { contra: Staphylococcus } \\
\text { aureus, Enterococcus } \\
\text { faecalis, Pseudomona } \\
\text { aeruginosa, } \\
\text { Escherichia coli, } \\
\text { Morganella } \\
\text { morganii e Klebsiella } \\
\text { pneumonia. }\end{array}$ \\
\hline
\end{tabular}

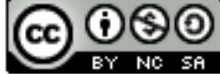


Citação (APA): Feitosa, A. do N. A., Freires, M. A. L., Sarmento, T. de A. B., Brito, L. M. de, Alencar Neta, R. L. de, \& Maracajá, P. B. (2020). Produtos Apícolas E Saúde Humana: Uma Revisão Integrativa. Brazilian Journal of Production Engineering, 6(7), 34-44.

\begin{tabular}{|c|c|c|c|c|}
\hline $\begin{array}{l}\text { Inhibitory } \\
\text { activity of } \\
\text { surfactin, } \\
\text { produced by } \\
\text { different Bacillus } \\
\text { subtilis subsp. } \\
\text { subtilis strains, } \\
\text { against Listeria } \\
\text { Monocytogenes } \\
\text { sensitive and } \\
\text { bacteriocin- } \\
\text { resistant strains }\end{array}$ & $\begin{array}{c}\text { Sabaté, D. C., \& } \\
\text { Audisio, M. C. } \\
\text { Argentina }\end{array}$ & $\begin{array}{c}\text { Microbiological } \\
\text { Research } \\
2013\end{array}$ & $\begin{array}{c}\text { Estudar o efeito da } \\
\text { surfactina, } \\
\text { produzida por } \\
\text { linhagens de } \\
\text { Bacillus subtilis, } \\
\text { isoladas do mel e } \\
\text { dos intestinos de } \\
\text { Apis mellifera, sobre } \\
\text { o patógeno } \\
\text { alimentar Listeria } \\
\text { monocytogenes } \\
\text { resistente e sensível } \\
\text { à bacteriocina. } \\
\end{array}$ & $\begin{array}{l}\text { Os resultados mostram } \\
\text { que a surfactina pode } \\
\text { ser considerada uma } \\
\text { alternativa natural para } \\
\text { prevenir e controlar } L \text {. } \\
\text { monocytogenes na } \\
\text { indústria alimentícia, } \\
\text { principalmente } \\
\text { naqueles resistentes à } \\
\text { bacteriocina. }\end{array}$ \\
\hline $\begin{array}{c}\text { Lactic acid } \\
\text { bacterial } \\
\text { symbionts in } \\
\text { honeybees - an } \\
\text { unknown key to } \\
\text { honey's } \\
\text { antimicrobial } \\
\text { and therapeutic } \\
\text { activities }\end{array}$ & $\begin{array}{c}\text { Olofsson, T. C. et } \\
\text { al. } \\
\text { Suécia }\end{array}$ & $\begin{array}{c}\text { International } \\
\text { Wound Journal } \\
2014\end{array}$ & $\begin{array}{l}\text { Mostrar a ação de } 13 \\
\text { bactérias ácido- } \\
\text { lácticas simbiontes, } \\
\text { presentes no mel, } \\
\text { sobre patógenos } \\
\text { animais e humanos, } \\
\text { a fim de analisar sua } \\
\text { aplicação na prática } \\
\text { clínica. }\end{array}$ & $\begin{array}{l}\text { O estudo mostrou que } \\
\text { tais simbiontes são } \\
\text { capazes de conter e } \\
\text { combater infecções } \\
\text { causadas por variados } \\
\text { patógenos animais e } \\
\text { humanos. }\end{array}$ \\
\hline $\begin{array}{c}\text { Activities of } \\
\text { Different Types } \\
\text { of Thai Honey } \\
\text { on Pathogenic } \\
\text { Bacteria Causing } \\
\text { Skin Diseases, } \\
\text { Tyrosinase } \\
\text { Enzyme and } \\
\text { Generating Free } \\
\text { Radicals }\end{array}$ & $\begin{array}{c}\text { Jantakee, K., \& } \\
\text { Tragoolpua, Y. } \\
\text { Tailândia }\end{array}$ & $\begin{array}{l}\text { Biological } \\
\text { Research } \\
2015\end{array}$ & $\begin{array}{c}\text { Investigar as } \\
\text { atividades } \\
\text { antibacterianas e } \\
\text { antioxidantes do mel } \\
\text { tailandês. }\end{array}$ & $\begin{array}{l}\text { O mel demonstra um } \\
\text { potencial imenso como } \\
\text { uma fonte útil que } \\
\text { fornece atividades anti- } \\
\text { radicais livres, anti- } \\
\text { tirosinase e } \\
\text { antibacteriana contra } \\
\text { bactérias patogênicas } \\
\text { que causam doenças de } \\
\text { pele. }\end{array}$ \\
\hline $\begin{array}{l}\text { A pilot study } \\
\text { investigating } \\
\text { lactic acid } \\
\text { bacterial } \\
\text { symbionts from } \\
\text { the honeybee in } \\
\text { inhibiting human } \\
\text { chronic wound } \\
\text { pathogens }\end{array}$ & $\begin{array}{c}\text { Butler, É. et al. } \\
\text { Suécia }\end{array}$ & $\begin{array}{c}\text { International } \\
\text { Wound Journal } \\
2016\end{array}$ & $\begin{array}{l}\text { Analisar o efeito do } \\
\text { uso tópico da } \\
\text { combinação entre } 13 \\
\text { simbiontes de } \\
\text { bactérias ácido- } \\
\text { lácticas, isolados de } \\
\text { abelhas, e mel no } \\
\text { manejo de } 22 \\
\text { pacientes com } \\
\text { feridas crônicas. }\end{array}$ & $\begin{array}{c}\text { Os autores } \\
\text { demonstraram que tal } \\
\text { combinação mostra-se } \\
\text { como uma alternativa } \\
\text { eficaz no tratamento } \\
\text { tópico de feridas } \\
\text { crônicas. }\end{array}$ \\
\hline $\begin{array}{c}\text { Antibacterial } \\
\text { synergic effect of } \\
\text { honey from two } \\
\text { stingless bees: } \\
\text { Scaptotrigona } \\
\text { bipunctata } \\
\text { Lepeletier, } 1836 \text {, } \\
\text { and } S . \text { postica } \\
\text { Latreille, } 1807\end{array}$ & $\begin{array}{c}\text { Nishio, E. K. et al., } \\
\text { Brasil }\end{array}$ & $\begin{array}{l}\text { Scientific } \\
\text { Reports } \\
2016\end{array}$ & $\begin{array}{l}\text { Avaliar a atividade } \\
\text { antimicrobiana do } \\
\text { mel produzido pelas } \\
\text { abelhas das espécies } \\
\text { Scaptotrigona } \\
\text { bipunctata (SB) e } \\
\text { Scaptotrigona } \\
\text { postica (SP) sobre } \\
\text { bactérias Gram- } \\
\text { positivas e Gram- } \\
\text { negativas. }\end{array}$ & $\begin{array}{l}\text { Demonstrou-se que o } \\
\text { mel natural possui } \\
\text { atividade } \\
\text { antimicrobiana in vitro } \\
\text { contra bactérias Gram- } \\
\text { positivas e Gram- } \\
\text { negativas, inclusive } \\
\text { contra as linhagens } \\
\text { multirresistentes. }\end{array}$ \\
\hline $\begin{array}{c}\text { Bee-derived } \\
\text { antibacterial } \\
\text { peptide, } \\
\text { defensin-1, } \\
\text { promotes wound } \\
\text { re- }\end{array}$ & $\begin{array}{l}\text { Bucekova, M. et } \\
\text { al. } \\
\text { Eslováquia/Itália }\end{array}$ & $\begin{array}{l}\text { Scientific } \\
\text { Reports } \\
2017\end{array}$ & $\begin{array}{l}\text { Demonstrar o } \\
\text { aumento da } \\
\text { produção de matriz } \\
\text { metaloproteinase-9 } \\
\text { (MMP-9) pelos } \\
\text { queratinócitos após }\end{array}$ & $\begin{array}{l}\text { O uso da geleia real é } \\
\text { capaz de aumentar a } \\
\text { taxa de cicatrização de } \\
\text { feridas, especialmente } \\
\text { devido à sua atividade } \\
\text { antimicrobiana, }\end{array}$ \\
\hline
\end{tabular}

\section{(c) (†) ()}


Citação (APA): Feitosa, A. do N. A., Freires, M. A. L., Sarmento, T. de A. B., Brito, L. M. de, Alencar Neta, R. L. de, \& Maracajá, P. B. (2020). Produtos Apícolas E Saúde Humana: Uma Revisão Integrativa. Brazilian Journal of Production Engineering, 6(7), 34-44.

\begin{tabular}{|c|c|c|c|c|}
\hline $\begin{array}{l}\text { epithelialisation } \\
\text { in vitro and in } \\
\text { vivo }\end{array}$ & & & $\begin{array}{l}\text { incubação com } \\
\text { extrato aquoso de } \\
\text { geleia real. }\end{array}$ & $\begin{array}{c}\text { prevenindo, dessa } \\
\text { forma, que os pacientes } \\
\text { portadores de feridas } \\
\text { extensas estejam } \\
\text { propensos a processos } \\
\text { infecciosos. }\end{array}$ \\
\hline $\begin{array}{l}\text { An insight into } \\
\text { the antibiofilm } \\
\text { properties of } \\
\text { Costa Rican } \\
\text { stingless bee } \\
\text { honeys }\end{array}$ & $\begin{array}{c}\text { Zamora, L. G. et } \\
\text { al. } \\
\text { Costa Rica }\end{array}$ & $\begin{array}{c}\text { Journal of } \\
\text { Wound Care } \\
2017\end{array}$ & $\begin{array}{l}\text { Examinar as } \\
\text { propriedades anti- } \\
\text { biofilmes do mel de } \\
\text { Tetragonisca } \\
\text { angustula. }\end{array}$ & $\begin{array}{c}\text { O mel produzido por } \\
\text { Tetragonisca angustula } \\
\text { na Costa Rica mostrou- } \\
\text { se um candidato } \\
\text { promissor para } \\
\text { pesquisas e } \\
\text { desenvolvimento de } \\
\text { novos curativos de } \\
\text { feridas, com foco no } \\
\text { tratamento do biofilme } \\
\text { de infecções de ferida } \\
\text { agudas e crônicas } \\
\text { causadas } \\
\text { Staphylococcus aureus. }\end{array}$ \\
\hline
\end{tabular}

Fonte: Autores, 2020.

A Tabela 1 revela que todos os estudos foram publicados na língua inglesa, e em periódicos internacionais. Nota-se, também, que apenas um estudo tem origem brasileira. Tendo em vista a riqueza da fauna e flora brasileiras, e a busca cada vez maior por métodos alternativos para tratamento de infecções e doenças devido à crescente resistência aos antimicrobianos, surpreende o fato de haver apenas um estudo brasileiro. Houve uma variedade em termos de países que publicaram trabalhos a respeito do tema, sendo a Suécia a mais representativa, com dois artigos publicados. Observa-se, também, que, após 2017, não houve nenhum outro estudo, revelando o preocupante desinteresse pelo tema. A Figura 1 mostra o percentual de publicações com relação ao ano, revelando que 2013, 2016 e 2017 tiveram duas publicações (25\%), cada, e que 2014 e 2015 apresentaram uma publicação (12,5\%), cada.

Figura 1. Percentual de publicações por ano.

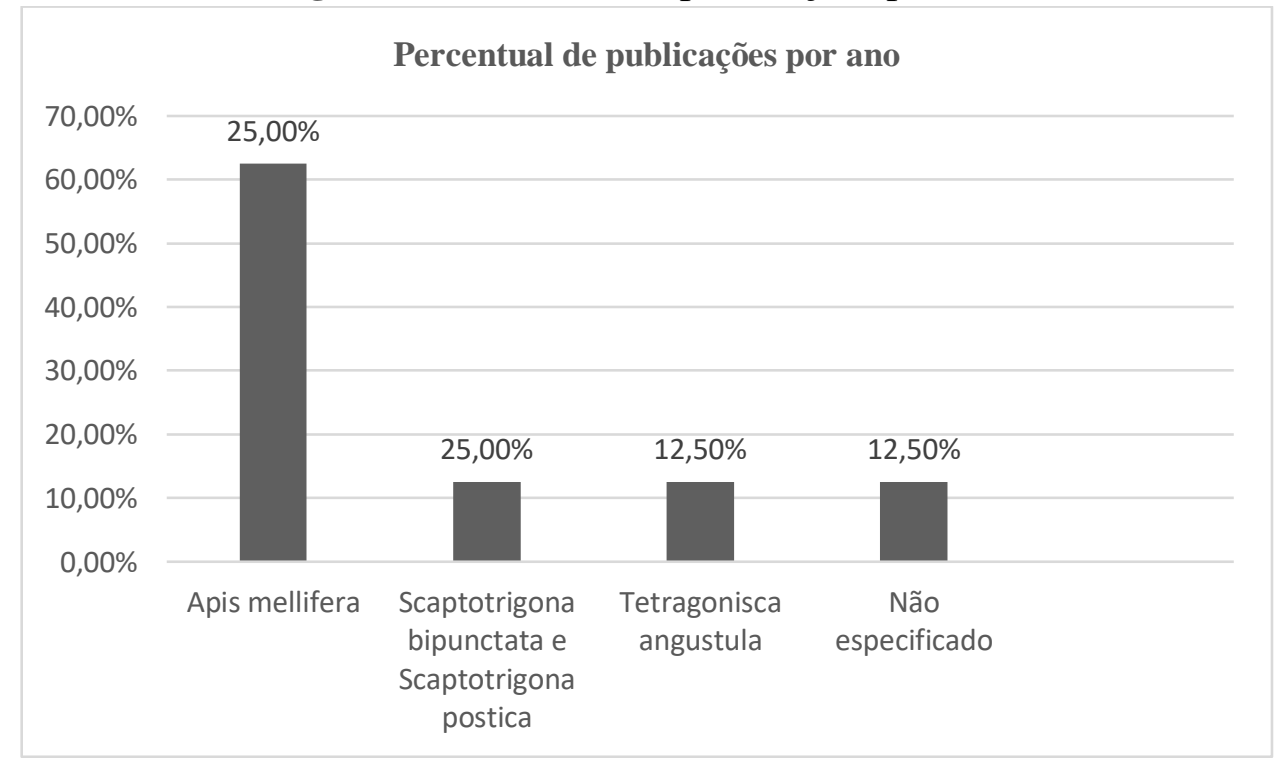

Fonte: Autores, 2020.

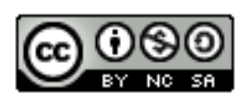


Figura 2. Principais espécies utilizadas nos trabalhos incluídos nesta revisão integrativa.

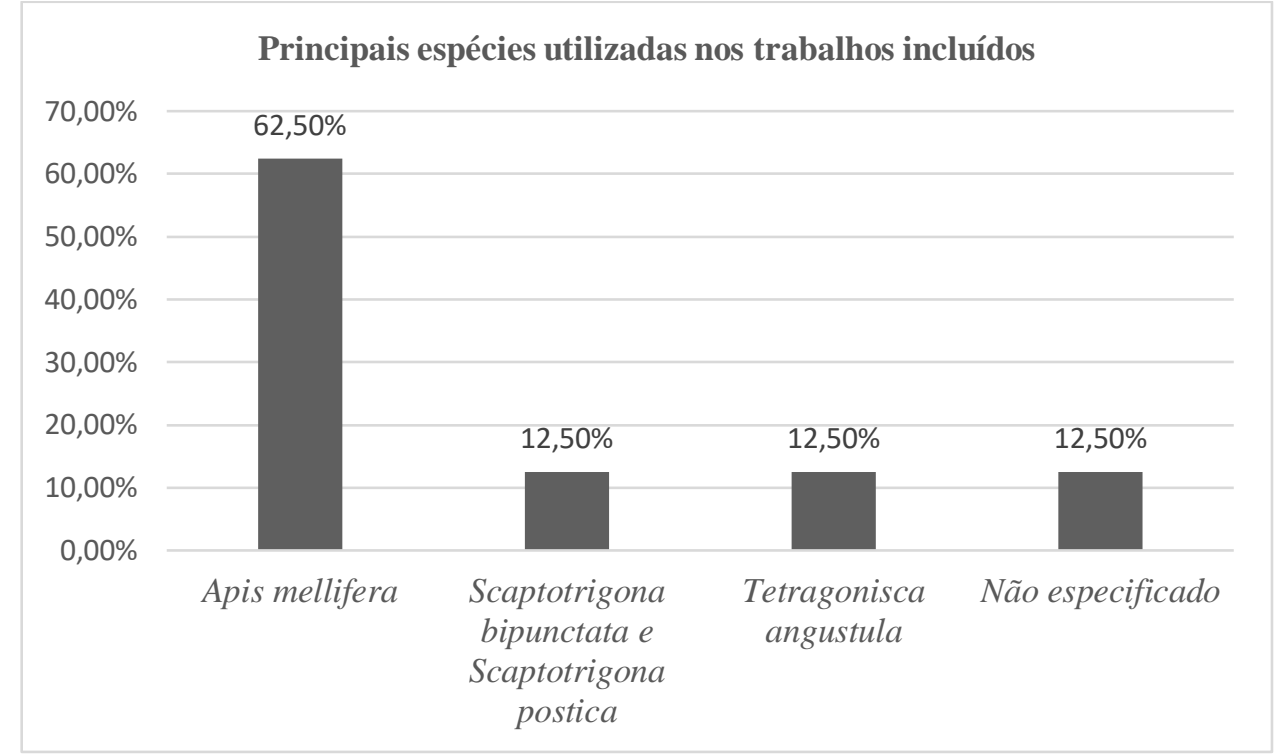

Fonte: Autores, 2020.

Em termos de espécies de abelhas estudadas, a Figura 2 mostra que a principal é a Apis mellifera (62,50\%), seguida de Scaptotrigona bipunctata e Scaptotrigona postica (12,50\%), e Tetragonisca angustula (12,50\%), sendo que um trabalho não especificou a espécie utilizada. A A. mellifera é uma espécie social, com ferrão, de origem europeia, justificando seu nome vulgar: abelha-europeia. Em 1839 foi introduzida no Brasil com o objetivo de suprir apiários na produção de mel e cera (Liberato \& Moraes, 2016).

As espécies Scaptotrigona bipunctata e Scaptotrigona postica, cujos nomes vulgares são tubuna (ou Mandaguari tubuna) e timba-amarela, respectivamente, são abelhas sem ferrão, ambas com ocorrência no Brasil. A diferença entre as duas está na sua coloração: a primeira possui cor preta, enquanto que a segunda possui coloração amarelo brilhante (Camargo \& Pedro, 2013; Oliveira, 2013).

Já a espécie Tetragonisca angustula é uma abelha sem ferrão, cujo nome vulgar é jataí e sua grande vantagem sobre as africanizadas ou europeias é sua capacidade de sobrevivência em diferentes ambientes, incluindo na zona urbana. Seu mel, além de ser suave e saboroso, é muito procurado devido às suas propriedades medicinais, sendo utilizado como fortificante e antiinflamatório, principalmente ocular (Raa, 2020).

Considerando-se os produtos apícolas utilizados nos estudos, têm-se a geleia real e o mel, sendo estes usados de maneira direta (Schinaider, et al., 2017). De forma indireta, foi realizado em dois estudos, um isolamento de 13 simbiontes de bactérias ácido-lácticas presentes no mel para analisar suas propriedades para aplicação na prática clínica, e, em um terceiro trabalho, estudouse o efeito da surfactina produzida por linhagens de Bacillus subtilis, isoladas do mel e intestino de A. mellifera (Butler et al., 2016; Olofsson et al., 2014; Sabaté \& Audisio, 2013).

Além de seu importante papel no equilíbrio ambiental, a abelha também possui destaque para alimentação e terapêutica humana, devido aos seus produtos (Amda, 2018). Um estudo, demonstrou que o mel produzido pela A. mellifera a partir da árvore Leptospermum scoparium

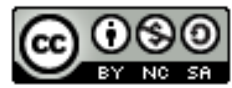


possui efeito antibiótico sobre aproximadamente 60 espécies de bactérias, incluindo aeróbicas, anaeróbicas, Gram-negativas e Gram-positivas. Este mesmo mel mostrou resultados positivos no tratamento de feridas infeccionadas por Staphylococcus aureus resistente à meticilina, e demais infecções causadas por Klebsiella pneumonia, Escherichia coli, Staphylococcus aureus, Serratia marcescens, Aspergillus nidulans, Bacillus subtillis, Bacillus cereus, Micrococcus luteus, Pseudomona aeruginosa, Salmonella typhimurum, Staphylococcus epidermidis e Enterobacter aerogene (Montenegro \& Mejías, 2013). O fato de tal mel apresentar efeito antimicrobiano sobre uma vasta diversidade de bactérias torna-o um grande aliado no combate a tais patógenos, principalmente quando já apresentam resistência a antibióticos, um sério problema de saúde pública, como já mencionado na introdução do presente artigo.

A surfactina é um lipopeptídeo produzido por linhagens de Bacillus subtilis com propriedades bactericida, fungicida e antiviral (Larini, et al., 2017). Tal bactéria é isolada do mel e dos intestinos de Apis mellifera, o objetivo do trabalho de Sabaté \& Audisio (2013) foi analisar as propriedades da surfactina para sua utilização na prática clínica, revelando-a como uma substância química e fisicamente estável para uso bactericida contra Listeria monocytogenes (Sabaté \& Audisio, 2013). Vale destacar que tal achado é de extrema relevância, tendo em vista que a L. monocytogenes, bactéria Gram-positiva e anaeróbica facultativa, é responsável pela meningite e septicemia, e sua infecção durante a gravidez frequentemente leva ao aborto ou ao parto prematuro, com alimentos contaminados como sua principal forma de transmissão (Bush, 2019).

Ainda neste contexto, dois estudos correlacionados revelaram os mecanismos relacionados com a ação antimicrobiana de 13 bactérias ácido-lácticas simbiontes extraídas de abelhas $A$. mellifera, e seu uso no tratamento de feridas crônicas em combinação com o mel puro (Butler, et al., 2016; Olofsson, et al., 2014). Os 13 simbiontes mostraram-se eficazes contra Serratia narcescens, Staphylococcus aureus, Klebsiella aerogenes, Citrobacter freundii, Pseudomonas aeruginosa, Enterobacter cloacae, Klebsiella oxytoca, Escherichia coli, Candida albicans, Enterococcus faecalis e Acinetobacter (Olofsson, et al., 2014). Com base nestes resultados, os autores realizaram culturas de feridas crônicas de 22 pacientes, nas quais cresceram os seguintes patógenos: S. aureus, E. faecalis, E. coli, E. cloacae, Proteus miribalis, P. aeruginosa, Finegoldia magna, Staphylococcus pettenkoferi, Stretptococcus dysgalactiae, Morganella moganii e Bacteroides fragilis, bactérias muito frequentes em lesões de difícil cicatrização. A combinação entre mel em spray ou gel e bactérias ácido-lácticas mostrou-se eficaz contra $S$. aureus, E. coli, E. cloacae, $P$. aeruginosa, S. pettenkoferi e $K$. oxytoca, sendo capaz de curar a ferida de 20 dos pacientes (90,9\%) (Butler, et al., 2016).

Ainda com relação ao tratamento de lesões de difícil cicatrização, o trabalho de Bucekova et al. (2017) demonstrou o potencial de repitelização do extrato aquoso da geleia real in vitro e in vivo (Bucekova, et al., 2017). A importância deste trabalho está no fato de que uma ferida aberta, exposta, está susceptível a processos infecciosos, podem trazer complicações graves aos seus portadores. Assim, ao se ter a capacidade de repitelização e facilitar o processo de cicatrização de tais lesões, pode-se evitar que tais pacientes contaminem-se e desenvolvam infecções.

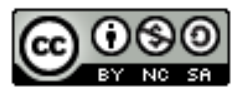


Em se tratando de infecções cutâneas, Staphylococcus epidermidis, S. aureus, Micrococcus luteus, Streptococcus pyogenes, P. aeruginosa, E. coli, K. pneumoniae e Enterococci como os principais causadores. $\mathrm{O}$ grande problema reside no fato de que algumas destas bactérias já apresentam resistência a antimicrobianos como meticilina e vancomicina, dificultando o tratamento de tais enfermidades. Corroborando com o trabalho de Montenegro \& Mejías (2013), Jantakee \& Tragoolpua (2015) comprovaram a atividade bactericida do mel tailandês sobre tais patógenos, inclusive contra aqueles multirresistentes. Tal capacidade é de extrema importância, principalmente na Tailândia, país de origem do estudo, o uso desse produto apícola no tratamento de infecções cutâneas pode ser um aliado na redução de gastos no sistema de saúde e dos próprios pacientes acometidos (Jantakee, \& Tragoolpua, 2015).

Considerando os dados de que $60 \%$ das infecções adquiridas em hospitais estão relacionadas com a formação de biofilme, Zamora, et al., (2017) evidenciaram que o mel de Tetragonisca angustula é capaz de destruir o biofilme de $S$. aureus, além de possibilitar a recuperação da atividade antimicrobiana da ampicilina e da vancomicina contra o biofilme de $S$. aureus, revelando, aqui, mais uma vez, o poder antimicrobiano do mel (Zamora, et al., 2017). Efeito similar foi encontrado no estudo de Nishio et al., (2016), considerando-se o mel de abelhas das espécies Scaptotrigona bipunctata (SB) e Scaptotrigona postica (SP) (Nishio, et al., 2016).

\section{CONCluSÃo}

O objetivo deste artigo foi analisar as propriedades antimicrobianas de dois produtos apícolas, a saber: mel e geleia real, através de uma revisão integrativa da literatura, encontrando-se oito artigos em uma única base de dados (PubMed), os quais compuseram a amostra final. O limite temporal talvez possa ter contribuído para este número relativamente pequeno, mas necessita de destaque o fato de que, após o ano de 2017, não houve mais nenhuma publicação sobre o tema.

Ademais, outra característica foi a presença de apenas um estudo brasileiro, de 2016, na amostra. O Brasil é uma terra com fauna e flora ricas, com um grande potencial para medicamentos naturais eficazes, porém, carece de estímulos governamentais e financeiros, principalmente.

Outro ponto de destaque consta na ausência de trabalhos abordando a atividade proposta no estudo em tela contra fungos. O que pode acontecer é o grande foco que se dá nas bactérias devido à presença de algumas espécies serem multirresistentes, representando um grave problema de saúde mundial, gerando ônus ao sistema de saúde e às pessoas acometidas. Todavia, fungos são seres vivos de relevância clínica, capazes de causar patologias graves nos seres humanos e, portanto, também merecem a atenção de estudiosos, incluindo o uso de produtos apícolas contra tais organismos.

Esta revisão foi capaz de revelar o grande potencial que especialmente o mel possui contra variadas linhagens de bactérias, incluindo-se, aqui, aquelas resistentes à meticilina e à vancomicina, auxiliando na cicatrização de feridas crônicas e no tratamento de infecções cutâneas, além de ter outras aplicações clínicas. A geleia real, neste sentido, mostrou-se eficaz no processo de repitelização, contribuindo para o processo de fechamento de lesões, e, podendo assim, ajudar na prevenção de que tais áreas sejam expostas a patógenos infecciosos.

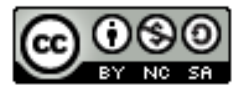


Por se tratar de uma revisão integrativa, este estudo apresentou limitações, como o fato de não incluir estudos com mais de 10 anos de publicação, trabalhos publicados em países limitados e, consequência, com populações específicas, as quais apresentam características específicas. Todavia, apresenta-se importante por ter reunido algumas utilidades do mel e da geleia real no tratamento de enfermidades humanas relevantes.

Por fim, sugere-se um maior aperfeiçoamento no desenvolvimento de novos estudos acerca do tema, principalmente no Brasil, e aplicando tais produtos em fungos e outros seres vivos de relevância clínica, com amostra bem delineadas, com o objetivo maior de auxiliar na oferta de uma assistência à saúde eficiente e de qualidade.

\section{REFERÊNCIAS}

Abelha. (2015). Associação Brasileira de Estudos das Abelhas. Apicultura. Disponível em: <https://abelha.org.br/apicultura/>. Acesso em: 13 jun. 2020.

Abelha. (2017). Associação Brasileira de Estudos das Abelhas. Espécies. Disponível em: <https://abelha.org.br/especies/>. Acesso em: 11 jun. 2020.

Amda. (2018). Associaçao Mineira de Defesa do Meio Ambiente. A importância das abelhas para oquilíbrio ambiental. Disponível em: $<$ https://www.amda.org.br/index.php/comunicacao/entrevistas/5377-a-importancia-dasabelhas-para-o-equilibrio-ambiental>. Acesso em: 18 jun. 2020.

Brasil. Ministério da Saúde. (2019). Práticas Integrativas e Complementares (PIC): quais são e para que servem. Disponível em: <https://saude.gov.br/saude-de-a-z/praticas-integrativas-ecomplementares>. Acesso em: 25 maio 2020.

Bucekova, M., Sojka, M., Valachova, I., Martinotti, S., Ranzato, E., Szep, Z., \& Majtan, J. (2017). Bee-derived antibacterial peptide, defensin-1, promotes wound re-epithelialisation in vitro and in vivo. Scientific reports, 7(1), 1-13.

Bush, L. M., Facp, M. D., Charles, E. (2019). Listeriose. Manual MSD. Disponível em: $<$ https://www.msdmanuals.com/pt/casa/infec\%C3\%A7\%C3\%B5es/infec\%C3\%A7\%C3\%B5e s-bacterianas-bact\%C3\%A9rias-gram-positivas/listeriose>. Acesso em: 18 jun. 2020.

Butler, É., Oien, R. F., Lindholm, C., Olofsson, T. C., Nilson, B., \& Vásquez, A. (2016). A pilot study investigating lactic acid bacterial symbionts from the honeybee in inhibiting human chronic wound pathogens. International Wound Journal, 13(5), 729-737.

Camargo, J. M. F., \& Pedro, S. R. M. (2013). Meliponini Lepeletier, 1836. In: Moure, J. S., Ubran, D., \& Melo, G. A. R. (orgs.). Catalogue of bees (Hymenoptera, Apoidea) in the Neotropical Region - online version. Disponível em: <http://moure.cria.org.br/catalogue?id=34936>. Acesso em: 18 jun. 2020.

Dorazio, B. (2017). As abelhas e seus produtos. Disponível em: $<$ http://g1.globo.com/sp/presidente-prudente-regiao/blog/nutricao-pratica/post/abelhas-e-seusprodutos.html>. Acesso em: 13 jun. 2020.

Duarte, M. (2019). Apicultura. Disponível em: <https://www.infoescola.com/zootecnia/apicultura/>. Acesso em: 13 jun. 2020.

Hofling, J. G. (2016). Isolamento e caracterização de fungos patogênicos de importância médica. Paco Editorial. 
Jantakee, K., \& Tragoolpua, Y. (2015). Activities of different types of Thai honey on pathogenic bacteria causing skin diseases, tyrosinase enzyme and generating free radicals. Biological Research, 48(1), 4.

Larini, M. M., Rezende, M. I., Ribeiro, M. L. L., \& Gasparin, F. G. M. (2017). Surfactina: estrutura, aplicações e fatores envolvidos em sua produção. Evidência, 17(2), 105-118.

Liberato, M. D. C. T. C., \& Morais, S. M. (2016) Produtos Apícolas do Ceará e Suas Origens Florais: características físicas, químicas e funcionais. EdUECE, 179 p.

Montenegro, G., \& Mejías, E. (2013). Biological applications of honeys produced by Apis mellifera. Biological research, 46(4), 341-345.

Neto, A. C. D., \& Rossi, C. G. F. (2018). Homeopatia: uma Revisão da Literatura. Revista de Ensino e Cultura, 1(4), 111.

Nishio, E. K., Ribeiro, J. M., Oliveira, A. G., Andrade, C. G. T. J., Proni, E. A., Kobayashi, R. K. T., \& Nakazato, G. (2016). Antibacterial synergic effect of honey from two stingless bees: Scaptotrigona bipunctata Lepeletier, 1836, and S. postica Latreille, 1807. Scientific reports, 6(1), 1-8.

Oliveira, A. (2013). Abelhas sem ferrão - Tubuna (Scaptotrigona bipunctata). Disponível em: <https://www.cpt.com.br/cursos-criacaodeabelhas/artigos/abelhas-sem-ferrao-tubunascaptotrigona-bipunctata>. Acesso em: 18 jun. 2020.

Olofsson, T. C., Butler, È., Markowicz, P., Lindholm, C., Larsson, L., \& Vásquez, A. (2016). Lactic acid bacterial symbionts in honeybees-an unknown key to honey's antimicrobial and therapeutic activities. International Wound Journal, 13(5), 668-679.

Opas, Organização Pan-Americana da Saúde. (2017). Folha informativa - resistência aos antibióticos. Disponível em: $<$ https://www.paho.org/bra/index.php?option=com_content\&view=article\&id=5664:folhainformativa-resistencia-aos-antibioticos\&Itemid=812>. Acesso em: 11 jun. 2020.

Raa, Revista Attalea Agronegócios. (2020). Abelha sem-ferrão: Jataí (Tetragonisca angustula). Disponível em: <https://revistadeagronegocios.com.br/abelha-sem-ferrao-jataitetragonisca-angustula/>. Acesso em: 18 jun. 2020.

Sabaté, D. C., \& Audisio, M. C. (2013). Inhibitory activity of surfactin, produced by different Bacillus subtilis subsp. subtilis strains, against Listeria monocytogenes sensitive and bacteriocin-resistant strains. Microbiological research, 168(3), 125-129.

Schinaider, A. D., Schinaider, A. D., Pucci, L. E. A., Rehfeld, C. S., \& Silva, D. F. O Comportamento do Consumidor de Mel: um Estudo de Caso Aplicado aos Acadêmicos do Curso de Zootecnia da UFSM-Campus Palmeira das Missões. In: Lopes, J. E. F. (Org.) Tópicos de Marketing, 1(1), 49-57.

Sousa, M. N. A., \& Santos, E. V. L. (2016). Medicina e pesquisa: um elo possível. Ed. 1, Editora Prismas.

Zamora, L. G., Beukelman, C. J., Berg, A. J. J. V., Aerts, P. C., Ufford, H. C. Q., Nijland, R., \& Arias, M. L. (2017). An insight into the antibiofilm properties of Costa Rican stingless bee honeys. Journal of Wound Care, 26(4), 168-177.

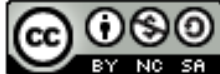

